\title{
Diagnostic echocardiographic features of the sinus venosus defect
}

Jose A Ettedgui, Ralph D Siewers, Robert H Anderson, Sang C Park, Elfriede Pahl, James R Zuberbuhler

\begin{abstract}
To establish the diagnostic criteria for a sinus venosus atrial septal defect cross sectional echocardiograms, cineangiograms, and surgical notes of all patients with this diagnosis seen at the Children's Hospital of Pittsburgh between 1986 and 1988 were reviewed. Seven patients were identified. In each the extent of the atrial septum and the nature of the junction of the superior vena cava with the atria were evaluated echocardiographically from the subcostal position. All had overriding of the superior vena cava and abnormally connected right pulmonary veins. Six patients had undergone cardiac catheterisation and cineangiography. Five patients underwent surgical repair. The operative findings were consistent with the expected morphology in all five, and these features were additionally confirmed in a specimen from the cardiopathological museum. Therefore, the basic anatomical feature of a superior sinus venosus interatrial communication is a biatrial connection of the superior vena cava. This, together with anomalous drainage of the right sided pulmonary veins, results in an interatrial communication outside the confines of the true atrial septum. Overriding of the superior vena cava across the upper rim of the oval fossa is suggested as the pathognomonic diagnostic feature that can clearly be demonstrated echocardiographically from the subcostal position. In essence the lesion is an interatrial communication rather than an atrial septal defect.
\end{abstract}

Interatrial communications are regarded as being among the simplest of congenital cardiac malformations; none the less, the echocardiographic distinction of the anatomical varieties has been far from certain. In morphological terms the key to diagnosis is that only those communications within the confines of the oval fossa are true "septal" defects. ${ }^{1}$ Of the other malformations permitting an interatrial communication, the ostium primum defect is really an atrioventricular septal defect ${ }^{2}$ whereas the rare coronary sinus defect is caused by unroofing of the course of the sinus through the left atrioventricular groove. The sinus venosus defect is the most difficult to identify. In 1907 the defect was recognised as overriding of the superior vena cava such that it achieved a biatrial connection $^{3}$; later Swan et al suggested ${ }^{4}$ that this was the consequence of persistence of venous connections between the right and left atria. Review of the anatomy confirms that, almost always, the important anatomical feature is biatrial connection of the superior vena cava which in effect produces an extraseptal interatrial conduit. With this morphology in mind, we examined the cross sectional echocardiographic features of those patients presenting recently at the Children's Hospital of Pittsburgh with a suspected diagnosis of the sinus venosus variant of interatrial communication.

\section{Patients and methods}

Since 1986, seven patients (four male and three female, aged 3-45 (median 4 years)) in whom a superior sinus venosus interatrial communication was diagnosed were evaluated by cross sectional echocardiography. In all patients the atrial septum and the junction between the superior vena cava and the atrial chambers had been carefully examined from the subcostal position with a Hewlett Packard 77020 sector scanner. Five of these patients have had cardiac catheterisation and four of these subsequently underwent surgical correction. One other patient (case 6) had surgery without previous cardiac catheterisation. The echocardiograms, angiograms, and surgical notes were reviewed. Two other patients were excluded when, on review, they were found to have left atrial isomerism. We also examined the single necropsy specimen in our cardiopathological museum with a sinus venosus interatrial communication.

\section{Results}

There is only one heart in the cardiopathological collection of the Children's Hospital of Pittsburgh that unequivocally shows the features of the sinus venosus interatrial communication. The major feature of this heart, which had undergone surgical repair, is an anomalous connection of the superior vena cava such that it connects directly to the roof of the left atrium in addition to having its anticipated right atrial connection along the terminal groove. As a consequence of this anomalous connection, the opening of the vein is equally committed to both right and left atria, overriding the rim of a normally formed oval fossa. The fossa itself was anatomically 
intact and the inferior vena cava and coronary sinus connected normally to the right atrium. Three right pulmonary veins, however, connected anomalously to the vena cava and its junction with the right atrium. Taken together, the anomalous venous connections formed an extensive interatrial communication outside the confines of the true atrial septum.

The table summarises the echocardiographic, cineangiographic, and surgical data of the seven patients. All seven patients examined echocardiographically showed an anomalous connection with the superior vena cava. This could be demonstrated only from the subcostal position. The arrangement is such that the superior vena cava overrides the atrial septum and there is a large interatrial communication (figure A). In all of them, the true atrial septum seemed to be intact, although Doppler evaluation showed patency of the oval fossa in two (cases 4 and 5). A right pulmonary vein was connected to the junction of the superior vena cava with the right atrium in all patients. An enlargement of the coronary sinus was noted in patients 1,3 , and 4 , and the presence of a persistent left superior vena cava was suspected.

Five patients underwent cardiac catheterisation (cases 1, 2, 3, 5, and 7). Angiography clearly delineated the abnormal connection with the superior vena cava in only one patient (case 2) (figure B). The junction of the superior vena cava with the right atrium was not profiled in the other four. The oval fossa was patent in four patients. A persistent left superior vena cava draining to the coronary sinus was found in patients 1 and 3 , in whom it was suspected echocardiographically. Absence of a brachiocephalic vein was shown by cineangiography but not by echocardiography. The right pulmonary venous connections were clearly displayed by cineangiography and were to the junction of the superior vena cava and the right atrium in all patients. Three patients had more than one pulmonary vein connection to this junction (cases 1, 2, and 5). One other patient (case 6) underwent surgical correction without prior cardiac catheterisation. In this patient one large and two small right sided pulmonary veins were found draining at the junction between the superior vena cava and the right atrium.

The operative note was consistent with the diagnosis of a sinus venosus interatrial communication in all five patients who had undergone surgical correction. In all the superior vena cava was overriding the superior limb of the oval fossa and had a biatrial connection.

Echocardiographic, cineangiographic, and surgical findings in sinus venosus interatrial communications

\begin{tabular}{|c|c|c|c|c|c|c|c|c|}
\hline \multirow{3}{*}{$\begin{array}{l}\text { Patient } \\
\text { No }\end{array}$} & \multirow[b]{3}{*}{ Age (yr) } & \multicolumn{3}{|c|}{ Echocardiography } & \multicolumn{3}{|c|}{ Cineangiography } & \multirow[b]{3}{*}{ Surgery } \\
\hline & & \multicolumn{3}{|c|}{ Connection } & \multicolumn{3}{|c|}{ Connection } & \\
\hline & & $S V C$ & $R P V$ & $A A$ & $s V C$ & $R P V$ & $A A$ & \\
\hline 1 & 5 & O & SVC-RA & LSVC & $\mathbf{U}$ & 2 & LSVC & SVD \\
\hline 2 & 3 & $\mathrm{O}$ & SVC-RA & & $\mathbf{O}$ & 2 & PFO & SVD \\
\hline 3 & 3 & o & SVC-RA & LSVC & $\mathbf{U}$ & SVC-RA & $\begin{array}{l}\text { LSVC } \\
\text { PFO }\end{array}$ & SVD \\
\hline 4 & 6 & O & SVC-RA & $\begin{array}{l}\text { LSVC } \\
\text { PFO }\end{array}$ & & & & \\
\hline 5 & 4 & O & SVC-RA & PFO & $\mathbf{U}$ & $\stackrel{2}{\text { SVC-RA }}$ & PFO & SVD \\
\hline $\begin{array}{l}6 \\
7\end{array}$ & $\begin{array}{l}45 \\
4\end{array}$ & O & $\begin{array}{l}\text { SVC-RA } \\
\text { SVC-RA }\end{array}$ & & $\mathbf{U}$ & SVC-RA & & SVD \\
\hline
\end{tabular}

AA, associated anomalies; LSVC, left superior vena cava draining to the coronary sinus; $O$, override; PFO, patent foramen ovale; RPV, right pulmonary vein; SVC-RA, superior vena cava-right atrial junction; SVC, superior vena cava; SVD, sinus venosus defect; U, unclear.

(A) Cross sectional echocardiogram from the subcostal position (patient 2) showing a large interatrial communication with overriding of the superior vena cava (closed arrows). The atrial septum was intact. (B) Cineangiogram from the same patient with the catheter in the left atrium through a patent oval fossa showing the abnormal communication (closed arrows) between the superior vena cava and an intact atrial septum (open arrows) $L A$, left atrium; $R A$, right atrium.
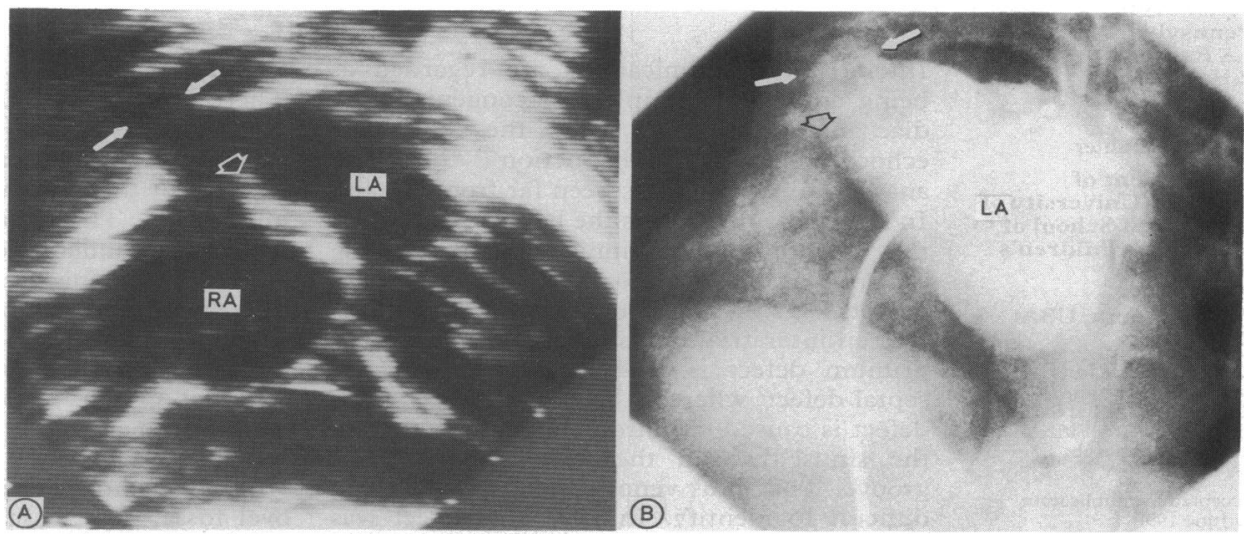


\section{Discussion}

The difference between an atrial septal defect and an interatrial communication is crucial in the differentiation of the various congenital malformations that produce the potential for atrial shunting. Only the secundum atrial septal defect is a true hole within the confines of the atrial septum. The ostium primum defect is caused by a deficiency of the atrioventricular septum and is diagnosed because of the stigmata of atrioventricular septal defects. ${ }^{56}$ Shunting through the rare coronary sinus defect occurs because of absence of the "common wall" that normally separates the sinus from the left atrium. It is, perhaps, the sinus venosus defect that is most difficult to understand and diagnose. Thus, in their echocardiographic study, Nasser and his colleagues state that the defect exists because "the atrial septum is deficient in its superior aspect". "When Abbott initially reviewed descriptions of the defect as long ago as 1907 , she, too, pointed to the "high" location of the defect but, significantly, placed great emphasis on the biatrial connection of the superior vena cava. ${ }^{3}$ It was Ross, in his review of the defect, who first highlighted its extraseptal location. ${ }^{8}$ This was subsequently confirmed by Swan et al, who appropriately described the lesion as an interatrial communication rather than a septal defect. ${ }^{4}$ This extraseptal location and the biatrial venous connection are the keys to both echocardiographic and surgical diagnosis. It was the biatrial venous connection that was the most obvious feature in our echograms, being present in all patients and better demonstrated by echocardiography than angiography. Disregard of this anatomical feature may account for the relatively low sensitivity in diagnosing this lesion in a recent study by cross sectional echocardiography with colour flow mapping. ${ }^{9}$ Anomalous right pulmonary venous connections were better detected angiographically as was presence or absence of the left brachiocephalic vein in the presence of a persistent left superior vena cava.

The diagnostic anatomical and echocardiographic criterion for which we now search in the sinus venosus defect is the overriding of the superior vena cava. Because of its extraseptal location it is better to describe this lesion as an interatrial communication rather than an atrial septal defect. We believe that the lesion would be better understood if it were regarded as a defect of the superior vena cava.

During the course of this investigation R H A was visiting professor supported by the Patrick Dick Memorial Fund. His full time appointment is at the National Heart and Lung Institute, London, supported by the British Heart and Joseph Levy Foundations.

1 Beerman LB, Zuberbuhler JR. Atrial septal defect. In Anderson RH, Macartney FJ, Shinebourne EA, Tynan MJ, eds. Pediatric cardiology. Edinburgh: Churchil Livingstone, 1987:541-62.

2 Becker AE, Anderson RH. Atrioventricular septal defects. What's in a name? $J$ Thorac Cardiovasc Surg 1982;83: 461-9.

3 Abbott ME. Congenital cardiac disease. In: Osler W, McCrae T, eds. Modern medicine-its theory and practice. Philadelphia: Lea and Febiger, 1907:349.

4 Swan HJC, Kirklin JW, Becu LM, Wood EH. Anomalous connection of right pulmonary veins to superior vena cava with interatrial cont pulmonary veins to superior vena cava eight cases. Circulation 1957;16:54-66.

5 Smallhorn JF, Tommasini G, Anderson RH, Macartney FJ Assessment of atrioventricular septal defects by two dimensional echocardiography. Br Heart J 1982;47: 109-21.

6 Silverman NH, Zuberbuhler JR, Anderson RH. Atrioventricular septal defects: cross sectional echocardiographic and morphologic comparisons. Int J Cardiol 1986;13: 309-31

7 Nasser FN, Tajik AJ, Seward JB, Hagler DJ. Diagnosis of sinus venosus atrial septal defects by two dimensional echocardiography. Mayo Clin Proc 1981;56:568-72.

8 Ross DN. The sinus venosus type of atrial septal defect. Guy's Hosp Rep 1956;105:376-81.

9 Khanderia BK, Shub C, Tajik J, Taylor CL, Hagler DJ, Saward JB. Utility of color flow imaging for visualizing shunt flow in atrial septal defect. Int J Cardiol 1989;23: 91-8. 